\title{
“EU FIZ MEU GAME": UM FRAMEWORK PARA CRIAÇÃO DE JOGOS DIGITAIS POR CRIANÇAS
}

\section{“I'VE MADE MY GAME": A FRAMEWORK FOR CREATING DIGITAL GAMES BY CHILDREN}

\section{“HICE MI JUEGO”: UN MARCO PARA CREAR JUEGOS DIGITALES PARA NIÑOS}

Resumo da tese: $\mathrm{O}$ estudo vinculado à linha de pesquisa de Políticas de Educação Básica e Superior e ao grupo de pesquisa Observatório de Políticas Educacionais do Programa de PósGraduação em Educação da Universidade do Vale do Itajaí tem por objeto de estudo a criação de jogos digitais por crianças. O problema consistiu em definir um framework de desenvolvimento de jogos digitais que faculte a atuação criadora de crianças com e sem deficiências no contexto da escola inclusiva. A tese defendida foi que um processo metodológico colaborativo e mediado propicia a atuação criadora de crianças com e sem

Submetido em: 26/04/2020 - Aceito em: 27/04/2020 - Publicado em: 29/04/2020

1 Doutora em Educação pela Universidade do Vale do Itajaí (Univali), professora do Programa de PósGraduação em Educação da Univali. adriana.alves@univali.br

${ }^{2}$ Doutora em Ciências da Educação pela Universidade Federal de Santa Catarina, Pós-doutorado no Institute of Education, University of London, Inglaterra, professora do Programa de Pós-Graduação em Educação da Univali. reginalh@univali.br. 
deficiências no desenvolvimento de jogos digitais. A tese se sustenta no entendimento de que o processo mediado - por instrumentos, signos e pessoas com diferentes níveis de experiências - e pautado na colaboração possibilita que as crianças passem de usuárias a criadoras de jogos, porque envolvidas em atividades intelectuais e afetivas de negociação, elaboração de hipóteses, desenvolvimento de ideias, análise de resultados e interação. O objetivo geral do estudo foi construir um processo metodológico mediado e colaborativo que faculte a atuação criadora de crianças com e sem deficiências no desenvolvimento de jogos digitais. Mais especificamente buscou-se: a) examinar as atividades, comportamentos e interação das crianças em experiências com jogos digitais e analógicos; b) avaliar as atividades de transposição de jogos digitais para analógicos e vice-versa; c) analisar a relação entre crianças, pesquisador e acadêmicos na mediação do processo de desenvolvimento de jogos digitais; d) identificar os avanços e dificuldades, processos e documentação com vistas a validação da metodologia proposta. Os referenciais teórico-metodológicos que ancoram a tese embasam-se nos pressupostos de abordagem histórico-cultural de Vygotski (1997, 2007, 2008, 2014), estreitamente relacionados a aprendizagem de alunos com deficiência intelectual e sua inclusão escolar: a coletividade, a colaboração, a experiência e a mediação simbólica. A partir de abordagem qualitativa de pesquisa, baseada no Design-Based Research (DBR) (WANG, HAFFANIN, 2005; BAUMGARTNER et al., 2003), buscou-se no processo metodológico assegurar profunda colaboração entre pesquisadores e participantes no alcance dos objetivos teóricos e práticos da pesquisa, resultando em mudanças educacionais práticas. Associada ao DBR utilizou-se a abordagem da análise narrativa que privilegia questões relacionadas às singularidades da experiência vivenciada e dos sujeitos que dela participaram (BAMBERG, 2012). Foram participantes da pesquisa quatro alunos com nove anos - dois meninos, sendo um deles diagnosticado com Autismo associado à deficiência intelectual, e duas meninas, uma com diagnóstico de deficiência intelectual - do $3^{\circ}$ ano do ensino fundamental de uma escola da rede pública de ensino de Itajaí, Santa Catarina. Mediante oficinas semanais, com duração de uma a duas horas, durante seis meses, foram desenvolvidas atividades orientadas com as crianças, empregando técnicas de construção de 
jogos das áreas de design de jogos e da computação e técnicas pedagógicas que requeriam o compartilhamento de ideias e a colaboração. A coleta de dados se deu por meio de registros fotográficos, filmagens, formulários e observação participante nas oficinas propostas. Os artefatos produzidos foram analisados com vistas a validar o construto da criação de um jogo digital pelo método empregado, destacando-se aqui o jogo digital construído em colaboração entre as crianças e acadêmicos nominado "Brinquedos que criam vida" ${ }^{3}$. Como resultado foi definido o framework "Eu fiz meu game" para desenvolvimento de jogos digitais com e por crianças no contexto escolar (ALVES, 2017) que requer a participação ativa dos envolvidos educadores, acadêmicos e crianças - por meio de atividades que englobam todas as etapas pedagógicas e de design para o desenvolvimento de um jogo digital. O processo é composto por quatro etapas: (i) Envolvimento, (ii) Experiência, (iii) Transposição e (iv) Criação de Jogos Digitais, e como ação transversal a mediação simbólica, que favorece o desenvolvimento cognitivo das crianças nas atividades propostas. $\mathrm{O}$ estudo evidenciou que a participação das crianças, notadamente as com deficiência intelectual, na construção de um jogo digital, e não somente em atividades de jogar, permitiram o desenvolvimento da imaginação e criatividade e consequentemente das funções psicológicas superiores, como habilidades de concentração, atenção, raciocínio, memória (auditiva, seletiva, sonora, visual), necessárias ao pensamento complexo, aliando os conceitos do design participativo às concepções de aprendizagem e desenvolvimento do campo da psicologia histórico-cultural desenvolvida por Vygotski.

Palavras-chave: inclusão escolar; ensino fundamental; práticas inovadoras; jogos digitais.

Agradecimentos: as autoras agradecem à CAPES e ao CNPq pela concessão de bolsas de pesquisa.

\footnotetext{
${ }^{3}$ Jogo disponível em https://univalildi.wixsite.com/univalildi/brinquedosquecriamvida
} 


\section{REFERÊNCIAS}

ALVES, Adriana Gomes. Eu fiz meu game: um framework para criação de jogos digitais por crianças. 2017. 287 f. Tese (Doutorado) - Curso de Doutorado em Educação, Programa de Pós-graduação em Educação, Universidade do Vale do Itajaí, Itajaí, 2017. Disponível em: https://www.univali.br/Lists/TrabalhosDoutorado/Attachments/142/Adriana\%20Gomes\%20A lves.pdf. Acesso em: 16 mar. 2017.

BAMBERG, M. NARRATIVE ANALYSIS. In: REIPS, U.-D. APA handbook of research methods in psychology: Research designs: Quantitative, qualitative, neuropsychological, and biological. [S.1.]: [s.n.], v. 2, 2012. Cap. 6, p. 291-310.

BAUMGARTNER, E. et al. Design-based research: an emerging paradigm for educational inquiry. Educational Researcher, 32, n. 1, January/February 2003. 5-8. Acesso em: 17 set. 2016.

VIGOTSKI, L. S. Imaginação e criatividade na infância. Tradução de João Pedro Fróis. São Paulo: WMF Martins Fontes, 2014. 125 p.

VIGOTSKY, L. S. A formação social da mente: o desenvolvimento dos processos psicológicos superiores. Tradução de José Cipolla Neto; Luís Silveira Menna Barreto e Solange Castro Afeche. 7. ed. São Paulo: Martins Fontes, 2007. 182 p.

VYGOTSKI, L. S. Obras Escogidas V: Fundamentos da defectología. Madrid: Visor Distribuiciones, 1997.

VYGOTSKY, L. S. Pensamento e linguagem. 4. ed. São Paulo: Martins Fontes, 2008.

WANG, F.; HAFFANIN, M. J. Design-based research and technology-enhanced learning environments. Educational technology research and development, 5, 2005. 1-6. 